\title{
Reductive dissolution of biogenic magnetite
}

\author{
Toshitsugu Yamazaki i
}

\begin{abstract}
Reductive dissolution of magnetite is known to occur below the Fe-redox boundary in sediments. In this study, detailed processes associated with biogenic magnetite dissolution are documented. A sediment core from the Japan Sea was used for this purpose, in which reductive dissolution of magnetic minerals is known to start at depths of about $1.15 \mathrm{~m}$ and is mostly complete within a depth interval of about $0.35 \mathrm{~m}$. Using first-order reversal curve diagrams, preferential dissolution of biogenic magnetite within this interval is estimated from the observation that a narrow peak that extends along the coercivity axis (central ridge), which is indicative of biogenic magnetite, diminishes downcore. Transmission electron microscopy is used to demonstrate that the sediments contain three magnetofossil morpho-types: octahedra, hexagonal prisms, and bullet-shaped forms. Within the reductive dissolution zone, partially etched crystals are commonly observed. With progressive dissolution, the proportion of bullet-shaped magnetofossils decreases, whereas hexagonal prisms become more dominant. This observation can be explained by the differences in resistance to dissolution among crystal planes of magnetite and the differences in surface area to volume ratios. Magnetofossil morphology may reflect the preference of magnetotactic bacterial lineages for inhabiting specific chemical environments in sediments. However, it could also reflect alteration of the original morphological compositions during reductive diagenesis, which should be considered when using magnetofossil morphology as a paleoenvironmental proxy.
\end{abstract}

Keywords: Biogenic magnetite, Magnetofossil, Reductive diagenesis, FORC diagram

\section{Introduction}

It is important to understand magnetic mineral diagenesis after deposition of sediments to constrain interpretation of paleomagnetic records and of paleoenvironments using rock-magnetic proxies (e.g., Roberts 2015). Associated with organic matter degradation, reduction from $\mathrm{Fe}^{3+}$ to $\mathrm{Fe}^{2+}$ begins after sequential progression of aerobic respiration, nitrate reduction, and manganese reduction. Below the Fe-redox boundary, where iron reduction starts, magnetic mineral dissolution may occur. The depth of the Fe-redox boundary in a sediment column varies from zero to tens of meters or more below the seafloor depending on various factors, including organic-carbon influx and bottom-water oxygen content. Reductive dissolution of magnetic minerals has

*Correspondence: yamazaki@aori.u-tokyo.ac.jp

Atmosphere and Ocean Research Institute, The University of Tokyo, Kashiwa, Japan been reported widely from various sediments (e.g., Karlin and Levi 1983; Canfield and Berner 1987; Yamazaki et al. 2003; Rowan et al. 2009; Korff et al. 2016). As reduction continues, sediments undergo sulfidic diagenesis and iron sulfide minerals like greigite and pyrite grow within the sediments (Rowan et al. 2009; Roberts 2015).

It is now recognized widely that biogenic magnetite is a major constituent of magnetic mineral assemblages in marine sediments that have not undergone reductive diagenesis (Roberts et al. 2011, 2012, 2013; Yamazaki and Ikehara 2012; Yamazaki and Shimono 2013). Biogenic magnetite may, thus, play an important role in sedimentary remanent magnetization acquisition (Kirschvink 1982; Ouyang et al. 2014; Chen et al. 2017). In addition, magnetofossil morphology may be a proxy for past sediment chemical conditions (Hesse 1994; Yamazaki and Kawahata 1998; Chang et al. 2018; Yamazaki et al. 2019). Biogenic magnetite undergoes reductive dissolution like magnetic minerals of other origins, and biogenic magnetite is inferred to be lost earlier than other magnetite types 
because of its finer grain sizes (Karlin 1990). Reductive dissolution of biogenic magnetite should influence paleomagnetic and paleoenvironmental interpretation, but the details of the dissolution processes have not been reported so far.

The purpose of this study is to document dissolution processes of biogenic magnetite during reductive diagenesis based on first-order reversal curve (FORC) diagrams and transmission electron microscope (TEM) observations. We discuss differences in resistance to reductive diagenesis depending on magnetofossil morphology.

\section{Material}

Sediment core GH98-1232 from the northern part of the Japan Sea at $44^{\circ} 48.09^{\prime} \mathrm{N}, 139^{\circ} 41.97^{\prime} \mathrm{E}$ was used for this study (Fig. 1). The water depth of the coring site is $838 \mathrm{~m}$, and the present-day Fe-redox boundary occurs a few centimeters below the sediment-water interface, which is recognized from a brown-to-gray change in sediment color. A rock-magnetic study by Yamazaki et al. (2003) revealed that reductive dissolution of magnetic minerals starts at depths of about $1.15 \mathrm{~m}$ in this core and is mostly completed within an interval of about $0.35 \mathrm{~m}$ (Fig. 2, Additional file 1: Table S1). Magnetic concentrationdependent parameters decrease rapidly downcore within this interval with the anhysteretic remanent magnetization (ARM) decreasing first, followed by the saturation

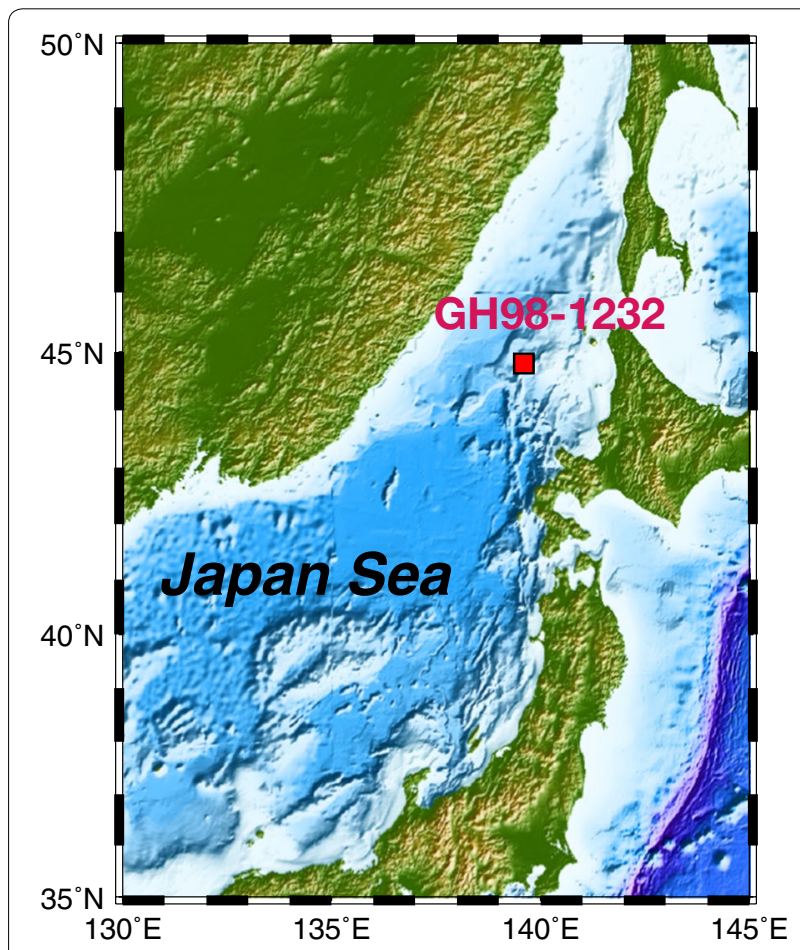

Fig. 1 Location of the studied core in the Japan Sea

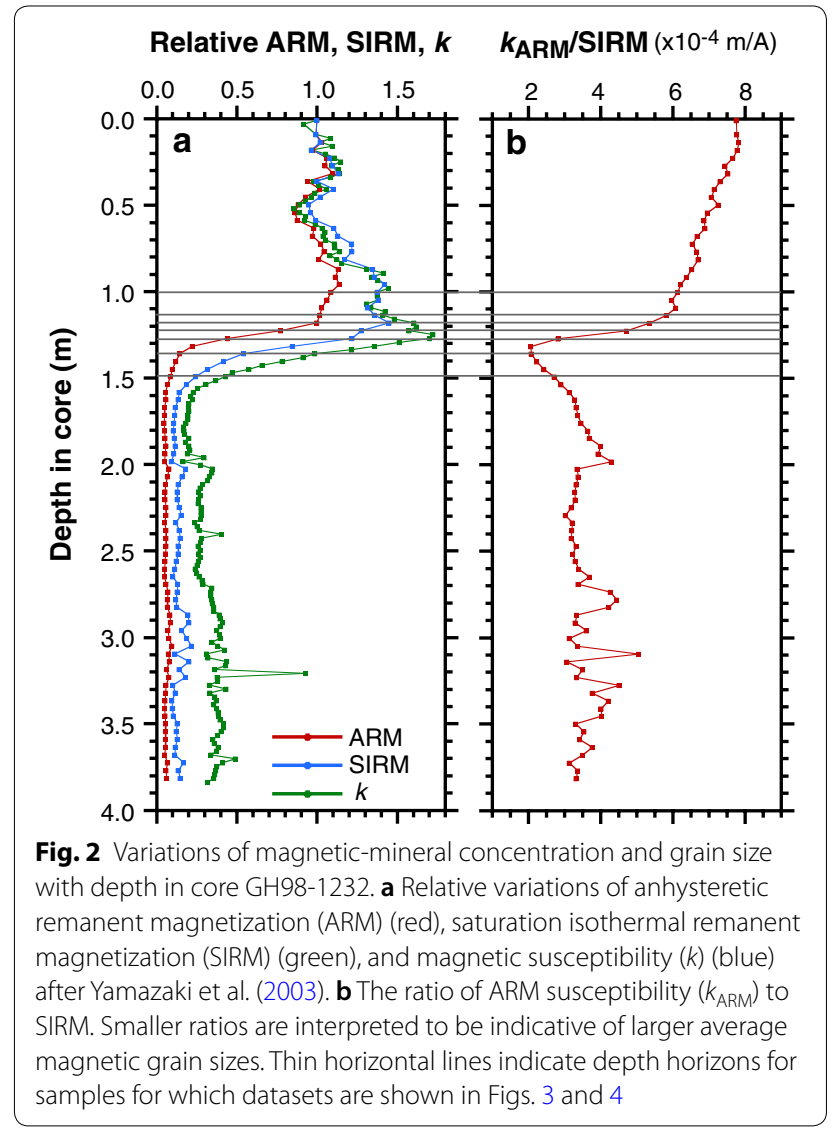

isothermal remanent magnetization (SIRM), and then the low-field magnetic susceptibility. Average magnetic grain size estimated from the ratio of ARM susceptibility $\left(k_{\text {ARM }}\right)$ to SIRM rapidly increases downcore from 1.18 to $1.35 \mathrm{~m}$, which indicates that finer magnetic grains are lost before larger grains. Average magnetic grain size then decreases a little between 1.35 and $1.6 \mathrm{~m}$. Based on S-ratio and low-temperature measurements, magnetite dominates the magnetic mineral assemblage of surface sediments to the depth at which dissolution initiates, and the relative proportion of high-coercivity minerals (e.g., hematite) increases with depth as magnetite dissolves preferentially in this interval (Yamazaki et al. 2003).

\section{FORC diagrams}

FORC diagrams are used widely in rock magnetism to elucidate the distribution of coercivities $\left(H_{c}\right)$ and magnetostatic interactions $\left(H_{u}\right)$ within magnetic particle assemblages, from which information on domain states, grain sizes and shapes, mineralogy, and spatial distribution of constituents can be obtained (e.g., Pike et al. 1999; Roberts et al. 2000, 2014). FORC diagrams are particularly useful for detecting biogenic magnetite in sediments; intact chains of biogenic magnetite behave as isolated 
non-interacting single-domain (SD) grains, which produce a characteristic narrow peak that extends along the coercivity axis at zero interaction field on a FORC diagram, called the "central ridge" (Egli et al. 2010; Li et al. 2012; Roberts et al. 2012; Yamazaki and Ikehara 2012; Chang et al. 2014).

FORC measurements were conducted at $\sim 5 \mathrm{~cm}$ stratigraphic intervals within and near the magneticmineral dissolution zone using an alternating-gradient magnetometer (Princeton Measurements Corporation MicroMag 2900) at the Geological Survey of Japan (GSJ), National Institute of Advanced Industrial Science and Technology (AIST). A total of 167 FORCs were measured for each sample, with $H_{c}$ between 0 and $100 \mathrm{mT}, H_{u}$ between -50 and $50 \mathrm{mT}$, and field spacing of approximately $1.3 \mathrm{mT}$. The maximum applied field was $1.0 \mathrm{~T}$, and the averaging time for each measurement point was $200 \mathrm{~ms}$. The FORCinel software (Harrison and Feinberg 2008, version 3.05 in 2019) was used to produce diagrams, and the VARIFORC algorithm of Egli (2013) was used to smooth the data with smoothing parameters of $S_{c 0}=4, S_{b 0}=3$, and $S_{c 1}=S_{b 1}=7$.

FORC diagrams above the magnetic-mineral dissolution zone $(1.00$ and $1.14 \mathrm{~m})$ have a sharp central ridge feature along the $H_{u}=0$ axis, which indicates the contribution of non-interacting SD grains (Fig. 3a). This SD signature is interpreted to be of biogenic origin. The FORC diagrams also have broad vertical spread with an elliptical peak at a coercivity of $10-15 \mathrm{mT}$, and outer contours diverge from the $H_{u}=0$ line toward the $H_{u}$ axis. This component is considered to be carried by a mixture of interacting SD, vortex state, and multi-domain (MD) grains (Roberts et al. 2000, 2014, 2017; Lascu et al. 2018), which are interpreted to be of terrigenous origin. Collapsed chains of biogenic magnetite may also be included in this component ( $\mathrm{Li}$ et al. 2012; Harrison and Lascu 2014). The contribution of the central ridge component decreases with depth within the dissolution zone, which is evident as a diminishing extracted central ridge signal with depth (Fig. 3b) and a downcore decrease of the proportion of the central ridge component to the broader, more vertically spread components on profiles along $H_{c}=40 \mathrm{mT}$ (Fig. 3c) and along $H_{u}=0$ (Fig. 3d). These observations indicate selective dissolution of biogenic magnetite. Coercivity distributions of both the biogenic and terrigenous components shift to lower values along with progressive reductive diagenesis (Fig. 3d); the peak coercivity of the biogenic component, initially $\sim 45 \mathrm{mT}$, decreases to $\sim 25 \mathrm{mT}$. This is probably due to decreasing grain volumes with dissolution. For the sample from the base of the dissolution zone at $1.49 \mathrm{~m}$, vertical spread becomes somewhat narrower and the proportion of the central ridge component increases a little compared with the sample from $1.36 \mathrm{~m}$.

\section{TEM observations}

TEM observations provide a direct way to investigate biogenic magnetite in sediments, which is complementary to FORC measurements. Biogenic magnetite can be identified directly in TEM images from its characteristic morphologies (bullet shaped, hexagonal prisms, and octahedra) and uniform SD grain sizes (Bazylinski et al. 1994; Kopp and Kirschvink 2008). Particle morphology is not known from FORC distributions, although particle elongation may be estimated from coercivity distributions (Egli 2004; Yamazaki and Ikehara 2012; Usui et al. 2017; Chang et al. 2018; Yamazaki et al. 2020). The limitation of TEM observations is, on the other hand, that a particle population under a TEM may not faithfully represent the original magnetic-mineral assemblage in a sample because magnetic-mineral extraction is required for observations. In this context, FORC distributions provide more quantitative information.

Magnetic minerals extracted from seven depths in the core, $1.00,1.14,1.18,1.23,1.27,1.36$, and $1.49 \mathrm{~m}$, were observed using a TEM. To extract magnetic minerals, sediments were first dispersed in distilled water with sodium hexametaphosphate using an ultrasonic bath, and magnetic minerals were then collected by circulating the dispersed sediments through a high magnetic field gradient. The magnetic extracts were dispersed in ethanol, and a small drop of the suspension was subsequently dried on a carbon-coated copper grid. A TEM (JEOL JEM-1400) at the Atmosphere and Ocean Research Institute, The University of Tokyo, operated at $120 \mathrm{kV}$, was used for the observations.

From morphologies seen in TEM images, magnetofossils were classified into three groups: bullet shaped, elongated, and equant (Fig. 4), although some ambiguity remains in estimating three-dimensional morphology from an image projected onto a plane. The elongated group consists of hexagonal prisms and elongated octahedra. The equant group is represented by cubo-octahedra, although short hexagonal prisms with length/ width ratios close to one are also included in this group. Bullet-shaped magnetofossils can be identified easily from their morphology. Relative abundances of biogenic magnetite from each morphological group and their grain-size distributions were obtained by counting several hundred grains in about 100 images for each sample. It should be noted that this kind of analysis remains semi-quantitative.

The sediments before reductive dissolution starts contain abundant magnetofossils of all three morpho-types (Fig. 4a), as reflected by the wide coercivity distribution 

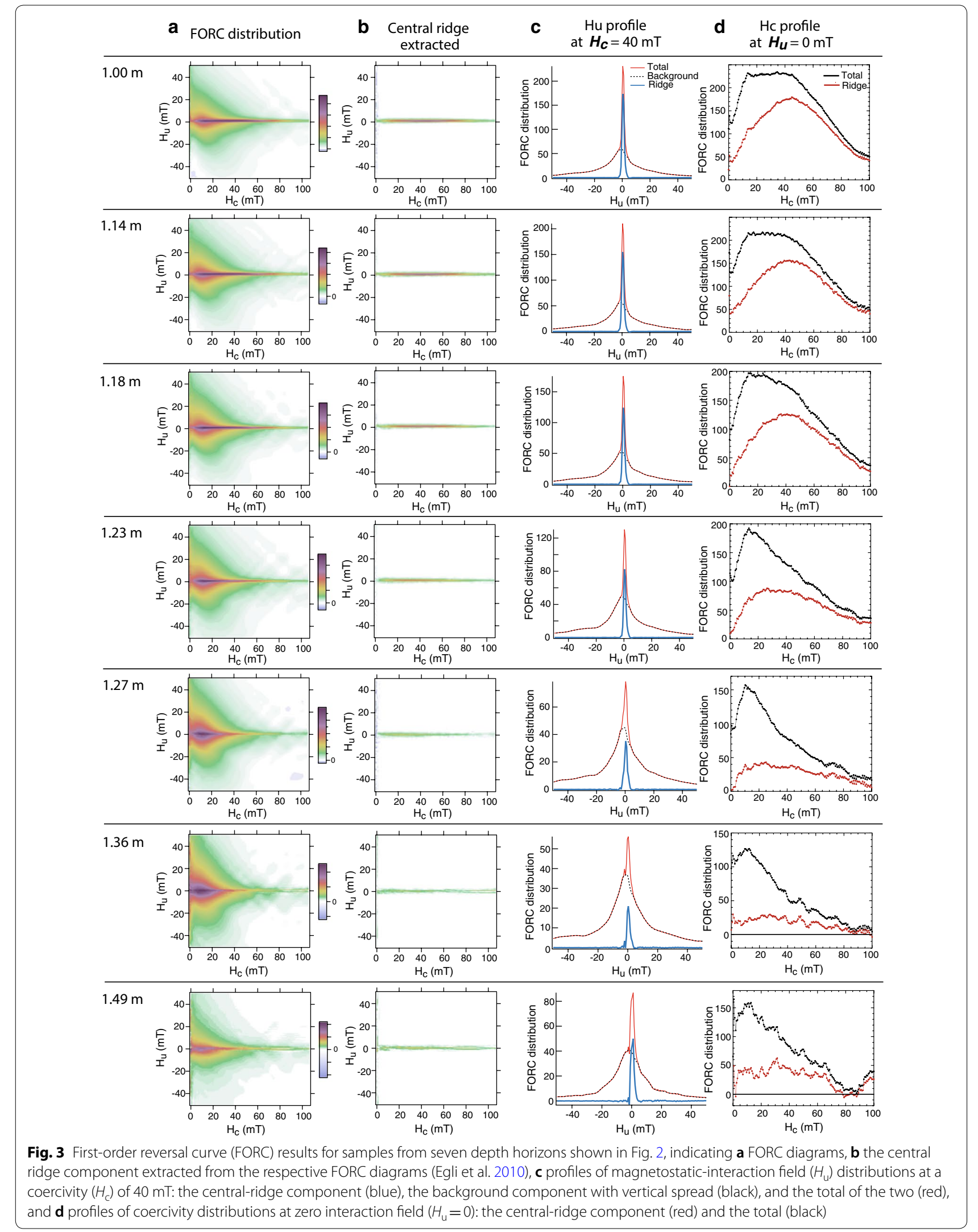

d Hc profile 

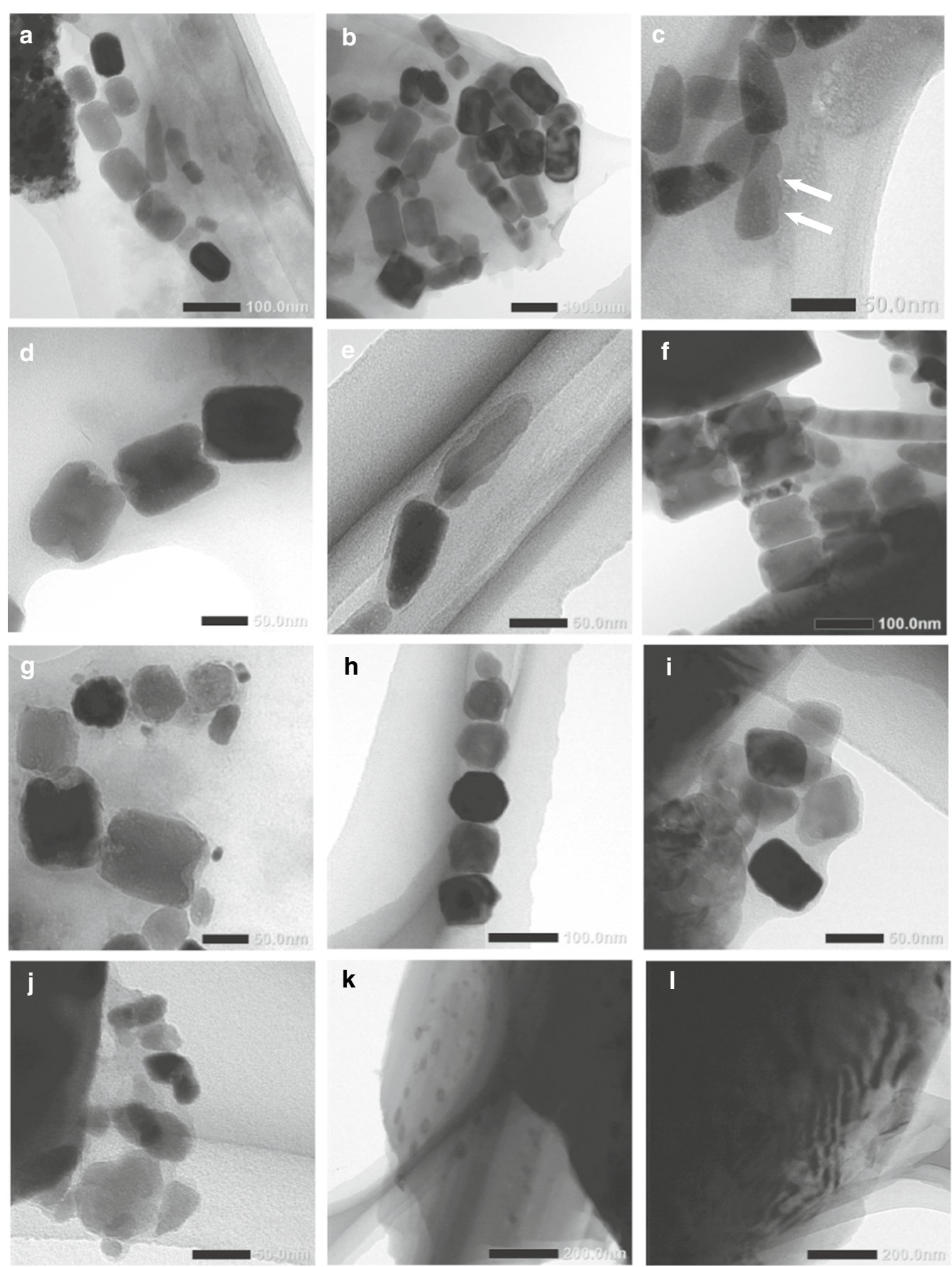

Fig. 4 Transmission electron microscope (TEM) images of magnetic extracts from seven depth horizons shown in Fig. 2. Samples from a $1.00 \mathrm{~m}, \mathbf{b}$, c $1.14 \mathrm{~m}, \mathbf{d}-\mathbf{f} 1.18 \mathrm{~m}, \mathbf{g}, \mathbf{h} 1.23 \mathrm{~m}, \mathbf{i}, \mathbf{j} 1.27 \mathrm{~m}, \mathbf{k} 1.36 \mathrm{~m}$, and $\mathbf{I} 1.49 \mathrm{~m}$. Magnetofossils in (a, b) have sharp crystal edges, whereas those of (c) through (j) are partially etched. Grains in $\mathbf{k}$, I are likely silicates with magnetic inclusions. Scale bar: $50 \mathrm{~nm}(\mathbf{c}-\mathbf{e}, \mathbf{g}, \mathbf{i}, \mathbf{j}), 100 \mathrm{~nm}(\mathbf{a}, \mathbf{b}, \mathbf{f}, \mathbf{h})$, and $200 \mathrm{~nm}(\mathbf{k}, \mathbf{l})$

along the central ridge of the FORC diagrams, from about 20 to $80 \mathrm{mT}$ (Fig. 3). At the beginning of the reductive dissolution interval at $1.14 \mathrm{~m}$, most of the biogenic magnetite has sharp crystal edges with little sign of dissolution in TEM images (Fig. 4b). However, some bullet-shaped magnetofossils have wavy crystal surfaces (Fig. 4c, arrows), which are indicative of partial dissolution. For the samples from 1.18 and $1.23 \mathrm{~m}$, at which dissolution is underway (Fig. 2), many crystals are partially etched (Fig. $4 \mathrm{~d}-\mathrm{g}$ ). It is often observed that the caps of 

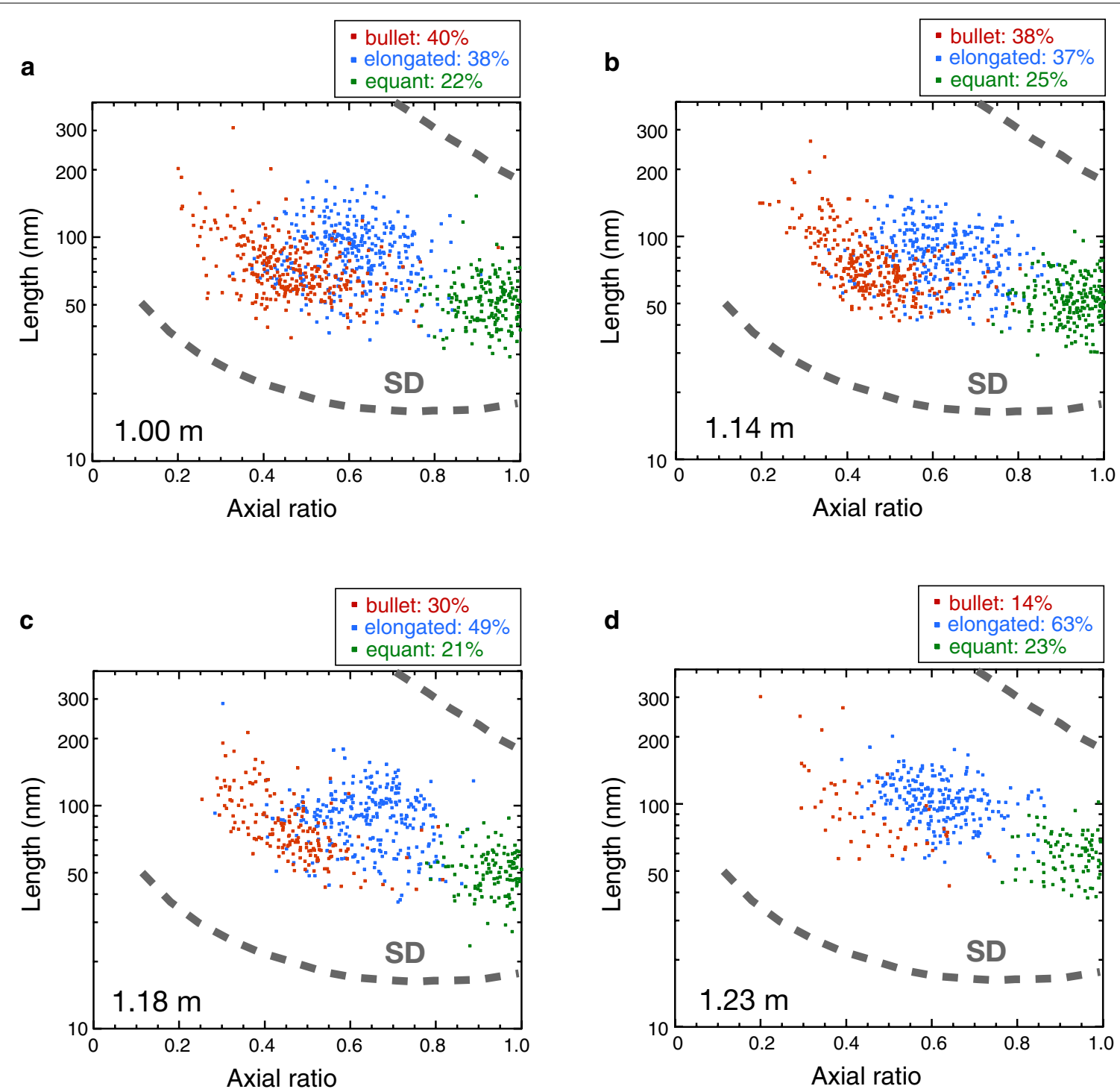

Fig. 5 Morphology and grain size of magnetofossils with respect to magnetic domain state. Samples are depths of a $1.00 \mathrm{~m}, \mathbf{b} 1.14 \mathrm{~m}, \mathbf{c} 1.18 \mathrm{~m}$, and $\mathbf{d} 1.23 \mathrm{~m}$ in the core. Magnetofossils are categorized into the three groups based on their morphology: bullet shaped (red), elongated (blue), and equant (green). Bold dashed curves indicate the maximum single-domain (SD) region for chains of magnetite particles with magnetostatic interactions after Muxworthy and Williams (2009)

hexagonal prisms, which are constituted by $\{111\}$ faces (Mann 1985; Meldrum et al. 1993), are etched, while side faces are almost intact (Fig. 4d, f). The wavy corrosion also affects bullet-shaped magnetofossils (Fig. 4e). Corroded equant magnetofossils have rounded shapes in general, which suggests that octahedral edges are corroded (Fig. $4 \mathrm{~g}, \mathrm{~h}$ ). In the lower part of the dissolution interval at $1.27 \mathrm{~m}$, the characteristic morphologies of biogenic magnetite are almost lost (Fig. 4i, j), although some particles are inferred to be of biogenic origin from their sizes within or near the SD range. At 1.36 and 1.49 m near the base of the dissolution interval, no magnetofossils remain. Some grains that resemble silicate-hosted magnetic inclusions (Chang et al. 2016a; Zhang et al. 2018) are observed (Fig. 4k, l).

Length/width distributions for each magnetofossil morpho-type determined in TEM images at four depths above and within the dissolution zone are shown in Fig. 5 and Additional file 2: Table S2. Bullet-shaped magnetofossils are lost before others, and magnetofossils of the elongated group are most resistant to reductive dissolution. The proportion of the bullet-shaped group is 40\% before dissolution starts, and decreases to $14 \%$ at $1.23 \mathrm{~m}$. 
On the other hand, the proportion of the elongated group increases from 38 to $63 \%$.

\section{Discussion}

FORC diagrams and TEM observations presented here reveal that biogenic magnetite dissolves preferentially in the interval between $\sim 1.15$ and $1.5 \mathrm{~m}$ in core GH981232, where magnetic-mineral dissolution was previously estimated from a rapid magnetic-mineral concentration decrease with an average grain-size increase. Biogenic magnetite generally has smaller grain size and hence higher surface area to volume ratio than terrigenous magnetic minerals, which is presumably responsible for the earlier dissolution of biogenic magnetite. Magnetite may also occur as inclusions within silicate minerals (Figs. 4k, l) and be protected from reductive dissolution (Chang et al. 2016a; Zhang et al. 2018; Usui et al. 2018). This contributes to the relative loss and preferential dissolution of biogenic magnetite with respect to detrital magnetite. In low-temperature measurements, the temperature of the maximum gradient in thermal decay curves of SIRM imparted at $6 \mathrm{~K}$ increases downcore from 106 to $118 \mathrm{~K}$ at about $1.5 \mathrm{~m}$ (Fig. 11 of Yamazaki et al. (2003)), which is close to the depth of magnetofossil disappearance. This indicates the usefulness of the method proposed by Chang et al. (2016b) for discriminating biogenic magnetite from the detrital counterpart using the Verwey transition temperature. The narrower vertical spread in the FORC diagram and the remaining central-ridge component at the base of the dissolution zone at $1.49 \mathrm{~m}$ (Fig. 3) may be explained by the presence of silicate-hosted magnetic mineral inclusions, which are resistant to dissolution. The inclusions would have smaller magnetostatic interactions compared with aggregated bare terrigenous magnetites, which were mostly dissolved by this depth. The rebound of the average magnetic grain size observed in $k_{\text {ARM }} /$ SIRM (Fig. 2b) may also be explained by the silicate-hosted magnetic inclusions; their grain sizes could be smaller than unprotected terrigenous magnetites.

This study reveals that resistance to reductive dissolution depends on magnetofossil morphology. With progressive reductive dissolution, the proportion of bullet-shaped magnetofossils decreases, whereas that of elongated magnetofossils, which mainly consist of hexagonal prisms, increases. Because of the short dissolution interval of $\sim 0.35 \mathrm{~m}$, changes of biogenic magnetite production associated with variations in sediment environments should be small. This is supported by the similarity of the proportions of individual morpho-types above $(1.00 \mathrm{~m})$ and at the top $(1.14 \mathrm{~m})$ of the dissolution interval (Fig. 5).

The morphological dependence of magnetofossil dissolution can be explained by differences of crystallographic planes in magnetite and their different susceptibility to reductive dissolution. Allen et al. (1988) reported that among the (111), (110), and (100) planes of magnetite, the dissolution rate in a reducing agent is the largest for the (111) plane and smallest for the (110) plane, and that the difference in dissolution rate is more than a factor of two. The difference was inferred to be due to the fact that the (111) plane has a close-packed array of oxygen atoms, which would be easily protonated under acidic conditions (Allen et al. 1988). Hexagonal prisms elongate in the [111] direction with $\{111\}$ caps and $\{110\}$ side faces (Mann 1985; Meldrum et al. 1993). The observations of TEM images from this study that $\{111\}$ caps of hexagonal prisms are often etched, whereas $\{110\}$ side faces are almost intact are consistent with the (111) plane being the most vulnerable to dissolution. Equant octahedral magnetofossils have eight $\{111\}$ faces that are truncated by apexes with $\{100\}$ faces (Mann et al. 1984). For bullet-shaped magnetite, a variety of crystal growth has been reported, but the development of $\{110\}$ faces is limited (Mann et al. 1987; Lefèvre et al. 2011; Li et al. 2015, 2020). Thus, hexagonal prismatic magnetofossils have larger proportions of resistant $\{110\}$ faces in their surfaces compared to equant octahedral and bullet-shaped magnetofossils. Furthermore, bullet-shaped magnetofossils have smaller axial ratios and have higher surface area to volume ratios than other morpho-types, which presumably leads also to the proportionally larger decrease of bullet-shaped magnetofossils with progressive reductive dissolution.

The morphology of magnetite produced by magnetotactic bacteria (MTB) is considered to be specific to phylum- or class-level lineages (Bazylinski et al. 1994; Kopp and Kirschvink 2008; Lefèvre and Bazylinski 2013), or may be even species specific (Li et al. 2020). Recent magnetic and microbiological studies have suggested that bullet-shaped magnetofossils are preferentially found in the oxic-anoxic transition zone (OATZ), which are produced by MTB of Nitrospirae lineage, whereas hexagonal prismatic and octahedral magnetofossils are distributed both above and within the OATZ positions (Yamazaki et al. 2019; Nakano et al. submitted to Environmental Microbiology Reports). Thus, magnetofossil morphology in sediments can be used as a proxy for past OATZ (Usui et al. 2017; Yamazaki et al. 2020). However, when studying reducing sedimentary environments (Rodelli et al. 2019), care is needed because of possible alteration of the original magnetofossil morphological compositions in the dissolution process. 


\section{Conclusions}

Biogenic magnetite particles with hexagonal prismatic, bullet-shaped, and octahedral morpho-types are abundant in the studied sediment core from the Japan Sea. When they undergo reductive diagenesis, bullet-shaped magnetofossils dissolve earlier than the other two morpho-types, whereas hexagonal prisms are the most resistant to dissolution. This observation can be explained by differences in resistance among crystal planes against reductive dissolution and differences in surface area to volume ratios. When magnetofossil morphology is used as a proxy for paleoenvironments, care is needed to ensure that interpretation is not biased by possible alteration of original magnetofossil morphological compositions during reductive diagenesis.

\section{Supplementary information}

Supplementary information accompanies this paper at https://doi. org/10.1186/s40623-020-01290-3.

Additional file 1: Table S1. Variations of magnetic-mineral concentration and grain size with depth in core GH98-1232.

Additional file 2: Table S2. Morphology and grain size of magnetofossil in TEM images.

\section{Abbreviations}

AIST: National Institute of Advanced Industrial Science and Technology; ARM: Anhysteretic remanent magnetization; FORC: First-order reversal curve; GSJ: Geological Survey of Japan; MD: Multidomain; MTB: Magnetotactic bacteria; OATZ: Oxic-anoxic transition zone; SD: Single domain; SIRM: Saturation isothermal remanent magnetization; TEM: Transmission electron microscope.

\section{Acknowledgements}

I thank Nobuhiro Ogawa for his assistance with TEM observations. I also thank Andrew Roberts, Liao Chang, and an anonymous reviewer for constructive comments, which greatly improved the manuscript. FORC measurements were conducted when I was an employee of GSJ, AIST.

\section{Authors' contributions}

TY designed the project, conducted the measurements, and wrote the manuscript. The author read and approved the final manuscript.

\section{Funding}

This work was supported by JSPS KAKENHI Grant Numbers 16K13896, 18K18789, and 19H01997.

\section{Availability of data and materials}

The data presented in Tables S1 and S2 are included in Additional files 1 and 2, respectively. Raw FORC measurements and TEM images are available from the author on request.

\section{Ethics approval and consent to participate}

Not applicable.

\section{Consent for publication}

Not applicable.

\section{Competing interests}

The author declares that he has no competing interests.

Received: 29 July 2020 Accepted: 4 October 2020

Published online: 17 October 2020
References

Allen GC, Kirby C, Sellers RM (1988) The effect of the low-oxidation state metal ion reagent tris-picolinatovanadium (II) formate on the surface morphology and composition of crystalline iron oxides. J Chem Soc Faraday Trans 1(84):355-364

Bazylinski DA, Garratt-Reed AJ, Frankel RB (1994) Electron microscopic studies on magnetosomes in magnetotactic bacteria. Microsc Res Tech 27:389-401

Canfield DE, Berner RA (1987) Dissolution and pyritization of magnetite in anoxic marine sediments. Geochim Cosmochim Acta 51:645-659

Chang L, Roberts AP, Winklhofer M, Heslop D, Dekkers MJ, Krigsman W, Fitz Gerald JD, Smith P (2014) Magnetic detection and characterization of biogenic magnetic minerals: a comparison of ferromagnetic resonance and first-order reversal curve diagrams. J Geophys Res Solid Earth 119:6136-6158

Chang L, Roberts AP, Heslop D, Hayashida A, Li J, Zhao X, Tian W, Huang Q (2016a) Widespread occurrence of silicate-hosted magnetic mineral inclusions in marine sediments and their contribution to paleomagnetic recording. J Geophys Res Solid Earth 121:8415-8431. https://doi. org/10.1002/2016JB013109

Chang L, Heslop D, Roberts AP, Rey D, Mohamed KJ (2016b) Discrimination of biogenic and detrital magnetite through a double Verwey transition temperature. J Geophys Res Solid Earth 121:3-14. https://doi. org/10.1002/2015JB012485

Chang L, Harrison RJ, Zeng F, Berndt TA, Roberts AP, Heslop D, Zhao X (2018) Coupled microbial bloom and oxygenation decline recorded by magnetofossils during the palaeocene-eocene thermal maximum. Nat Com 9:4007. https://doi.org/10.1038/s41467-018-06472-y

Chen L, Heslop D, Roberts AP, Chang L, Zhao X, McGregor HV, Marino G, Rodriguez-Sanz L, Rohling EJ, Pälike H (2017) Remanence acquisition efficiency in biogenic and detrital magnetite and recording of geomagnetic paleointensity. Geochem Geophys Geosyst 18:1435-1450. https://doi. org/10.1002/2016GC006753

Egli R (2004) Characterization of individual rock magnetic components by analysis of remanence curves. 2. Fundamental properties of coercivity distributions. Phys Chem Earth 29:851-867

Egli R (2013) VARIFORC: an optimized protocol for calculating non-regular firstorder reversal curve (FORC) diagrams. Glob Planet Change 110:302-320

Egli R, Chen AP, Winklhofer M, Kodama KP, Horng CS (2010) Detection of noninteracting single domain particles using first-order reversal curve diagrams. Geochem Geophys Geosyst 11:11. https://doi.org/10.1029/2009G C002916

Harrison RJ, Feinberg JM (2008) FORCinel: an improved algorithm for calculating first-order reversal curve distributions using locally weighted regression smoothing. Geochem Geophys Geosyst 9:Q05016. https://doi. org/10.1029/2008GC001987

Harrison RJ, Lascu I (2014) FORCulator: a micromagnetic tool for simulating first-order reversal curve diagrams. Geochem Geophys Geosyst 15:4671-4691

Hesse PP (1994) Evidence for bacterial palaeoecological origin of mineral magnetic cycles in oxic and sub-oxic Tasman Sea sediments. Mar Geol 117:1-17

Karlin R (1990) Magnetite diagenesis in marine sediments from the Oregon continental margin. J Geophys Res 95:4405-4419

Karlin R, Levi S (1983) Diagenesis of magnetic minerals in recent haemipelagic sediments. Nature 303:327-330

Kirschvink JL (1982) Paleomagnetic evidence for fossil biogenic magnetite in western Crete. Earth Planet Sci Lett 59:388-392

Korff L, von Dobeneck T, Frederichs T, Kasten S, Kuhn G (2016) Cyclic magnetite dissolution in Pleistocene sediments of the abyssal northwest Pacific Ocean: evidence for glacial oxygen depletion and carbon trapping. Paleoceanography 31:600-624. https://doi.org/10.1002/2015PA002882

Kopp RE, Kirschvink JL (2008) The identification and biogeochemical interpretation of fossil magnetotactic bacteria. Earth-Sci Rev 86:42-61

Lascu I, Einsle JF, Ball MR, Harrison RJ (2018) The vortex state in geologic materials: a micromagnetic perspective. J Geophys Res Solid Earth 123:7285-7304. https://doi.org/10.1029/2018JB015909

Lefèvre CT, Pósfai M, Abreu F, Lins U, Frankel RB, Bazylinski DA (2011) Morphological features of elongated-anisotropic magnetosome crystals in magnetotactic bacteria of the Nitrospirae phylum and the Deltaproteobacteria class. Earth Planet Sci Lett 312:194-200 
Lefèvre CT, Bazylinski DA (2013) Ecology, diversity, and evolution of magnetotactic bacteria. Microbiol Mol Biol Rev 77:497-526

Li J, Wu W, Liu Q, Pan Y (2012) Magnetic anisotropy, magnetostatic interactions and identification of magnetofossils. Geochem Geophys Geosyst 13:51. https://doi.org/10.1029/2012GC004384

Li J, Menguy N, Gatel C, Boureau V, Snoeck E, Patriarche G, Leroy E, Pan Y (2015) Crystal growth of bullet-shaped magnetite in magnetotactic bacteria of the Nitrospirae phylum. J R Soc Interface 12:20141288. https://doi. org/10.1098/rsif.2014.1288

Li J, Menguy N, Roberts AP, Gu L, Leroy E, Bourgon J, Yang X, Zhao X, Liu P, Changela HG, Pan Y (2020) Bullet-shaped magnetite biomineralization within a magnetotactic Deltaproteobacterium: implications for magnetofossil identification. J Geophys Res Biogeosci 125:20. https://doi. org/10.1029/2020JG005680

Mann S (1985) Structure, morphology, and crystal growth of bacterial magnetite. In: Kirschvink JL, Jones DS, MacFadden BJ (eds) Magnetite biomineralization and magnetoreception in organisms. Plenum, New York, pp 311-332

Mann S, Frankel RB, Blakemore RP (1984) Structure, morphology and crystal growth of bacterial magnetite. Nature 310:405-407

Mann S, Sparks NHC, Blakemore RP (1987) Structure, morphology and crystal growth of anisotropic magnetite crystals in magnetotactic bacteria. Proc R Soc Lond B 231:477-487

Meldrum FC, Mann S, Heywood BR, Frankel RB, Bazylinski DA (1993) Electron mircroscopy study of magnetosomes in a cultured coccoid magnetotactic bacteria. Proc R Soc Lond B 251:231-236

Muxworthy AR, Williams W (2009) Critical superparamagnetic/single-domain grain sizes in interacting magnetite particles: implications for magnetosome crystals. J R Soc Interface 6:1207-1212. https://doi.org/10.1098/ rsif.2008.0462

Ouyang T, Heslop D, Roberts AP, Tian C, Zhu Z, Qiu Y, Peng X (2014) Variable remanence acquisition efficiency in sediments containing biogenic and detrital magnetites: implications for relative paleointensity signal recording. Geochem Geophys Geosyst 15:2780-2796. https://doi. org/10.1002/2014GC005301

Pike CR, Roberts AP, Verosub KL (1999) Characterizing interactions in fine magnetic particle systems using first order reversal curves. J Appl Phys 85:6660-6667

Roberts AP (2015) Magnetic mineral diageresis Earth-Sci Rev 151:1-47

Roberts AP, Pike CR, Verosub KL (2000) First-order reversal curve diagrams: a new tool for characterizing the magnetic properties of natural samples. J Geophys Res 105:28461-28475

Roberts AP, Florindo F, Villa G, Chang L, Jovane L, Bohaty SM, Larrasoaña JC, Heslop D, Fitz Gerald JD (2011) Magnetotactic bacterial abundance in pelagic marine environments is limited by organic carbon flux and availability of dissolved iron. Earth Planet Sci Lett 310:441-452

Roberts AP, Chang L, Heslop D, Florindo F, Larrasoaña JC (2012) Searching for single domain magnetite in the "pseudo-single domain" sedimentary haystack: implications of biogenic magnetite preservation for sediment magnetism and relative paleointensity determinations. J Geophys Res 117:B08104. https://doi.org/10.1029/2012JB009412

Roberts AP, Florindo F, Chang L, Heslop D, Jovane L, Larrasoaña JC (2013) Magnetic properties of pelagic marine carbonate. Earth-Sci Rev 127:111-139
Roberts AP, Heslop D, Zhao X, Pike CR (2014) Understanding fine magnetic particle systems through use of first-order reversal curve diagrams. Rev Geophys 53:557-602. https://doi.org/10.1002/2014RG000462

Roberts AP, Almeida TP, Church NS, Harrison RJ, Heslop D, Li Y, Li J, Muxworthy AR, Williams W, Zhao X (2017) Resolving the origin of pseudo-single domain magnetic behavior. J Geophys Res Solid Earth 122:9534-9558. https://doi.org/10.1002/2017JB014860

Rodelli D, Jovane L, Giorgioni M, Rego ES, Cornaggia F, Benites M, Cedraz P, Berbel GBB, Braga ES, Ustra A, Abreu F, Roberts AP (2019) Diagenetic fate of biogenic soft and hard magnetite in chemically stratified sedimentary environments of Mamanguá Ría, Brazil. J Geophys Res Solid Earth 124:2313-2330. https://doi.org/10.1029/2018JB016576

Rowan CJ, Roberts AP, Broadbent T (2009) Reductive diagenesis, magnetite dissolution, greigite growth and paleomagnetic smoothing in marine sediments: a new view. Earth Planet Sci Lett 277:223-235

Usui Y, Yamazaki T, Saitoh M (2017) Changing abundance of magnetofossil morphologies in pelagic red clay around Minamitorishima, western North Pacific. Geochem Geophys Geosyst 18:4558-4572

Usui Y, Shimono T, Yamazaki T (2018) Rock magnetism of quartz and feldspars chemically separated from pelagic red clay: a new approach to provenance study. Earth Planets Space 70:133. https://doi.org/10.1186/s4062 3-018-0918-1

Yamazaki T, Kawahata H (1998) Organic carbon flux controls the morphology of magnetofossils in marine sediments. Geology 26:1064-1066

Yamazaki T, Ikehara M (2012) Origin of magnetic mineral concentration variation in the Southern Ocean. Paleoceanography 27:2206. https://doi. org/10.1029/2011PA002271

Yamazaki T, Shimono T (2013) Abundant bacterial magnetite occurrence in oxic red clay. Geology 41:1191-1194

Yamazaki T, Abdeldayem AL, Ikehara K (2003) Rock-magnetic changes with reduction diagenesis in Japan Sea sediments and preservation of geomagnetic secular variation in inclination during the last 30,000 years. Earth Planets Space 55:327-340

Yamazaki T, Suzuki Y, Kouduka M, Kawamura N (2019) Dependence of bacterial magnetosome morphology on chemical conditions in deep-sea sediments. Earth Planet Sci Lett 513:135-143

Yamazaki T, Fu W, Shimono T, Usui Y (2020) Unmixing biogenic and terrigenous magnetic mineral components in red clay of the Pacific Ocean using principal component analyses of first-order reversal curve diagrams and paleoenvironmental implications. Earth Planets Space 72:120. https://doi. org/10.1186/s40623-020-01248-5

Zhang Q, Liu Q, Li J, Sun Y (2018) An integrated study of the eolian dust in pelagic sediments from the North Pacific Ocean based on environmental magnetism, transmission electron microscopy, and diffuse reflectance spectroscopy. J Geophys Res Solid Earth 123:3358-3376

\section{Publisher's Note}

Springer Nature remains neutral with regard to jurisdictional claims in published maps and institutional affiliations.

\section{Submit your manuscript to a SpringerOpen ${ }^{\circ}$ journal and benefit from:}

- Convenient online submission

- Rigorous peer review

- Open access: articles freely available online

- High visibility within the field

- Retaining the copyright to your article

Submit your next manuscript at $\boldsymbol{\nabla}$ springeropen.com 